\title{
METABOLISM OF LITHOCHOLIC ACID IN BILE FISTULA PATIENTS*
}

\author{
By JAMES B. CAREY, JR., ANd GALE WILLIAMS
}

\author{
(From the Department of Medicine, University of Minnesota Medical School and Hospitals, \\ Minneapolis, Minn.)
}

( Submitted for publication September 27, 1962; accepted December 6, 1962)

Lithocholic acid ${ }^{1}$ is rapidly hydroxylated by the rat liver to $\beta$-muricholic acid (1) and at least two other compounds more hydrophilic than lithocholic acid (2). In man, this acid is sometimes present in small quantities in the bile (3) and feces (4), and it is postulated that it may be formed by $7 \alpha$ dehydroxylation of chenodeoxycholic acid by colon bacteria (5). In order to determine if the human liver changes the lithocholic acid molecule into any other compounds, the labeled acid was given intravenously to two patients, each having a total external biliary fistula.

\section{METHODS AND RESULTS}

Labeled lithocholic acid ( $3 \alpha$-hydroxycholanic acid-24$\left.\mathrm{C}^{14}\right)$ was prepared from the norbromide by nitrile synthesis (6). Purity of the labeled acid was established by repeated crystallizations from ethanol, acetone, and acetic acid which yielded specific activities differing by less than $10 \%$. Column chromatography with systems I and II (see Table I) demonstrated homogenous behavior and constant specific activity after admixture of the labeled acid with authentic lithocholic acid on both types of columns. Descending paper chromatography using system $\mathrm{V}$ showed the labeled acid to have the same movement and color of fluorescence with antimony trichloride (11) as lithocholic acid controls. No impurities were detected.

Approximately $12 \mu \mathrm{c}$ of the authentic labeled acid, specific activity $7.8 \times 10^{6} \mathrm{cpm}$ per $\mathrm{mg}$, was dissolved in a small volume of ethanol and slowly injected through the tubing of an iv saline drip into patient C.A., and approximately $27 \mu \mathrm{c}$ of the same acid was similarly given to a second patient, L.R. All bile was collected in ethanol. The final volume of each fraction collected was adjusted to contain $50 \%$ ethanol and stored at $5^{\circ} \mathrm{C}$.

Information concerning the patients. Patient C.A., a 72-year-old woman, had a carcinoma of the gall bladder.

\footnotetext{
* Supported by U. S. Public Health Service grant A-713.

${ }^{1}$ Chief substances referred to are: lithocholic acid, $3 \alpha$-hydroxycholanic acid; $\beta$-muricholic acid, $3 \alpha, 6 \beta, 7 \beta$ trihydroxycholanic acid; chenodeoxycholic acid, $3 \alpha, 7 \alpha-$ dihydroxycholanic acid; deoxycholic acid, $3 \alpha, 12 \alpha$-dihydroxycholanic acid; and cholic acid, $3 \alpha, 7 \alpha, 12 \alpha$-trihydroxycholanic acid.
}

At laparotomy, four metastatic nodules were seen in the liver adjacent to the gall bladder, but elsewhere the liver was smooth. There were metastases to the peritoneum, omentum, and lymph nodes surrounding the common bile duct, which was slightly dilated. Although the patient was not jaundiced (total serum bilirubin, $0.4 \mathrm{mg}$ per 100 $\mathrm{ml}$ ), common duct occlusion was considered imminent, choledochal enterostomy was not possible, and consequently $\mathrm{T}$-tube drainage of the common duct was established 28 days before administration of the labeled lithocholic acid. The patient never became jaundiced, felt well, and was ambulatory until a few days before she died of intestinal obstruction 6 weeks after the experiment. Bile salts were discontinued 10 days before the experiment began. Laboratory values on the day the study began were: total serum bilirubin, $0.6 \mathrm{mg}$ per 100 $\mathrm{ml}$; alkaline phosphatase $17.6 \mathrm{King}$-Armstrong $\mathrm{U}$; cephalin cholesterol flocculation, $2+$; and blood urea nitrogen, $16 \mathrm{mg}$ per $100 \mathrm{ml}$. Serum electrolytes were normal.

Patient L.R., a 74-year-old woman, had a carcinoma of the common bile duct that did not occlude it, but extended to the duodenum, causing intestinal obstruction that was corrected by partial duodenectomy, cholecystectomy, and placement of a T-tube in the common bile duct. She was not jaundiced at the time of surgery (total serum bilirubin, $0.5 \mathrm{mg}$ per $100 \mathrm{ml}$; bromsulfalein retention, $7 \%$; alkaline phosphatase, 8 King-Armstrong $U$ ). During the experiment, started 104 days after surgery, the patient was ambulatory and felt well, and laboratory values were: total serum bilirubin, $0.3 \mathrm{mg}$ per $100 \mathrm{ml}$; bromsulfalein retention, $2 \%$; and alkaline phosphatase, 10.3 King-Armstrong U. Bile salts were discontinued 2 weeks before the experiment. The patient was discharged from the hospital feeling well.

Radioactivity and urobilinogen content of feces. In order to estimate the extent of exclusion of bile from the intestines, all stools for the 4 days immediately after administration of the isotope were collected, combined, and assayed for radioactivity by Van Slyke's wet combustion technique using a vibrating-reed electrometer to count the $\mathrm{C}^{14} \mathrm{O}_{2}$. It was found that less than $1 \%$ of the administered radioactivity was recoverable in the stools of either patient. The urobilinogen content of the feces was $0.6 \mathrm{mg}$ per day for C.A. and $0.4 \mathrm{mg}$ per day for L.R. These findings are compatible with virtually complete exclusion of bile from the intestine (12).

Excretion of radioactivity in the bile. Of the administered radioactivity, $88.4 \%$ was excreted in the bile of C.A. and $69 \%$ in L.R. The cumulative percentage of the radioactivity collected in the bile is plotted against time 
TABLE I

Chromatographic systems employed for bile acid separations

\begin{tabular}{|c|c|c|c|}
\hline System & Column size & Stationary phase & Moving phase \\
\hline I & $1 \times 30 \mathrm{~cm}$ & $70 \%$ acetic acid & $\begin{array}{l}\text { Increasing concentrations of isopropyl } \\
\text { ether in hexane }(7)\end{array}$ \\
\hline II & $1 \times 10 \mathrm{~cm}$ & $95 \%$ methanol & $\begin{array}{l}\text { Increasing concentrations of isopropyl } \\
\text { ether in hexane }(7)\end{array}$ \\
\hline III & $1 \times 30$ or $3.6 \times 30 \mathrm{~cm}$ & $70 \%$ acetic acid & $\begin{array}{l}\text { Increasing concentrations of benzene in } \\
\text { hexane ( } 8)\end{array}$ \\
\hline 11 & Whatman 3-mm paper & $70 \%$ acetic acid & Butanol-ethylene chloride, 10:90 (9) \\
\hline $\mathrm{V}$ & Whatman 3-mm paper & $70 \%$ acetic acid & Isopropyl ether-heptane, 20:80 (10) \\
\hline
\end{tabular}

in Figure 1, which shows that over $85 \%$ of the radioactivity found in the bile was excreted within the first 12 hours and more than $95 \%$ in the first 24 hours. The isotope content of whole bile was determined by placing $0.1 \mathrm{ml}$ of the $50 \%$ bile-ethanol mixture directly on stainless steel planchets in triplicate and using a gas-flow counter.

Fractionation of radioactiaity in bilc. Suitable samples (10 to $20 \mathrm{ml}$ ) of the bile-ethanol mixture were evaporated nearly to dryness, water was added, the $\mathrm{pH}$ was adjusted to less than 1 with concentrated $\mathrm{HCl}$, and the mixture was extracted with butanol. The butanol extracts were evaporated under nitrogen and hydrolyzed with $4.5 \mathrm{~N}$ $\mathrm{NaOH}$ in sealed glass tubes at $130^{\circ} \mathrm{C}$ for 5 hours. The hydrolysate was diluted with water, the $\mathrm{pH}$ was adjusted to less than 1 with concentrated $\mathrm{HCl}$, and the mixture was extracted three times with equal volumes of ethyl ether. Less than $2 \%$ of the activity remained in the aqueous phase.

The evaporated ether extract was chromatographed with system III. Radioactivity in samples from each fraction was measured by use of stainless steel planchets

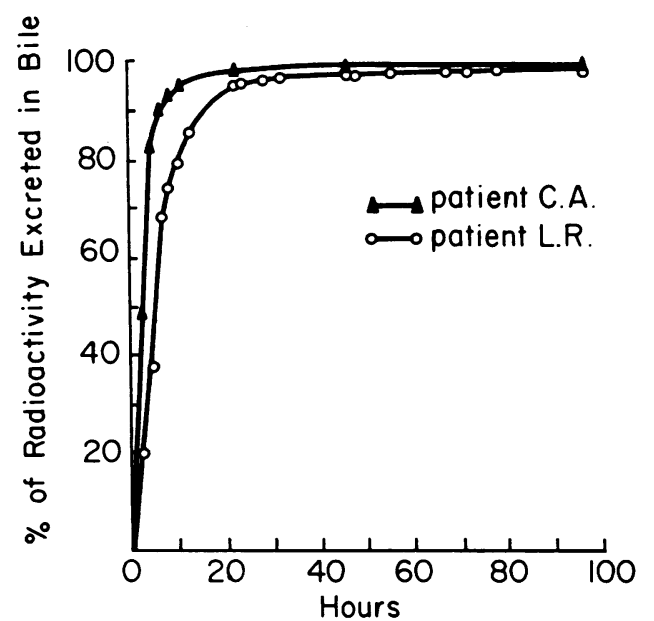

Fig. 1. Cumulative percentage of Radioactivity exCRETED IN FISTULA BILE AFTER INTRAVENOUS ADMINISTRATION OF 24-C ${ }^{14}$-LITHOCHOLIC ACID. and a gas-flow counting chamber. The remainder of each fraction was titrated with $0.01 \mathrm{~N} \mathrm{NaOH}$. The distribution of radioactivity in the bile of L.R. is shown in Figure 2. More than $90 \%$ of the isotope found in the bile was eluted with hexane in the same fractions where lithocholic acid is found. Very small amounts (less than 2 to $3 \%$ ) of radioactivity were eluted in 20 and $40 \%$ benzene fractions.

The hexane fractions from bile excreted for the first 3 days after administration of the labeled lithocholic acid contained $98.7 \%$ of all the radioactivity excreted in the bile. These fractions were combined, evaporated, and dissolved in $50 \%$ ethanol. The $\mathrm{pH}$ was adjusted to about 8 with $7 \mathrm{~N} \mathrm{NaOH}$, and the mixture was extracted with

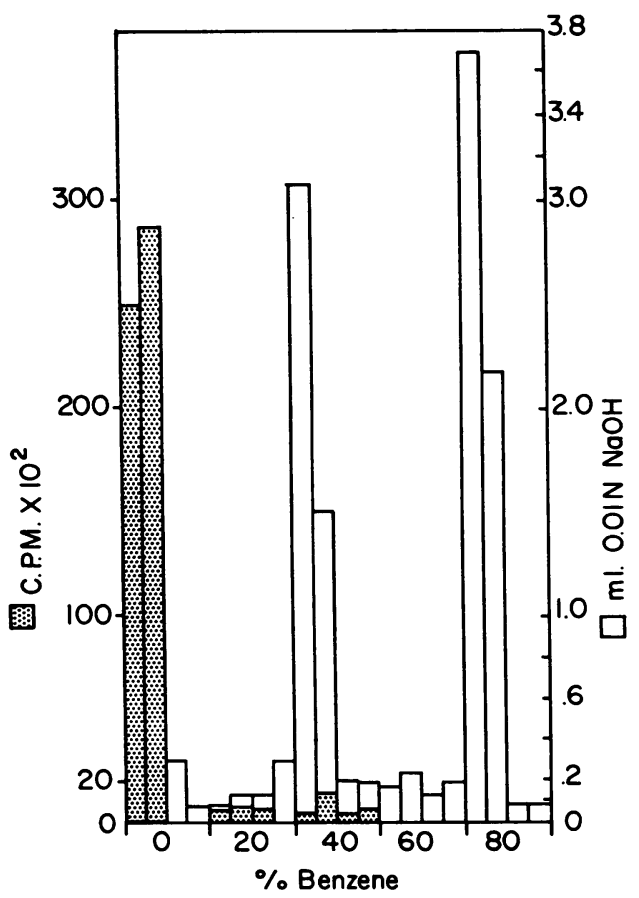

Fig. 2. Distribution of Radioactive compounds in FISTULA BILE AFTER INTRAVENOUS ADMINISTRATION OF 24$\mathrm{C}^{14}$-Lithocholic Acid. See system III. Table I. 


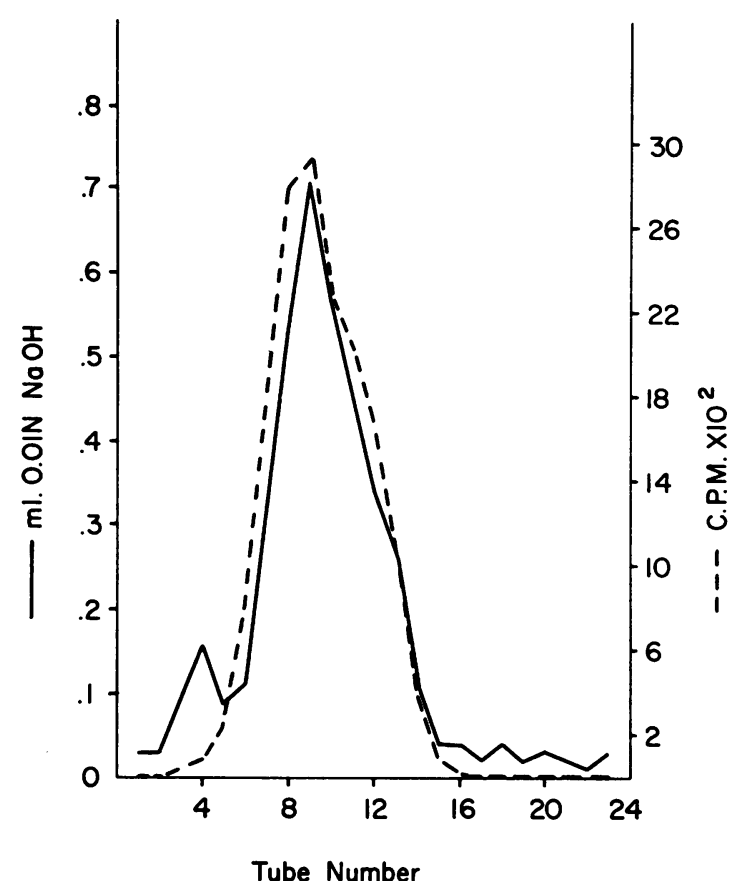

Fig. 3. Chromatography OF RADIOACTIVE LithoChOLIC ACID FRACTION OF BILE WITH UNLABELED LITHOCHOLIC ACID IN System I, TABLE I. Radioactivity, broken line; titration, solid line.

ethyl ether. After the ether was backwashed with dilute $\mathrm{NaOH}$, no radioactivity remained in it. The aqueous phases were then diluted with an equal volume of water, the $\mathrm{pH}$ was adjusted to less than 1 with concentrated

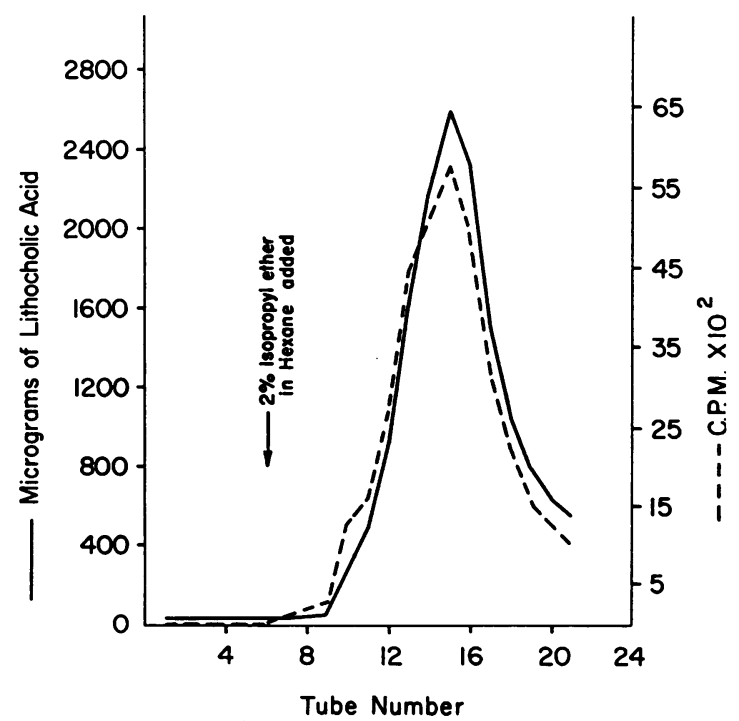

Fig. 4. Chromatography of tUbes 5 through 14 (FigURE 3) CONTAINING RADIOACTIVE LITHOCHOLIC ACID FRACTION OF BILE AND ADDED UNLABELED LITHOCHOLIC ACID. System II, Table I. Radioactivity, broken line; micrograms of lithocholic acid, solid line.
$\mathrm{HCl}$, and again the mixture was extracted repeatedly with ethyl ether until the final wash extracted no additional radioactivity.

The ether phase was evaporated to a small volume, 20 $\mathrm{mg}$ of authentic lithocholic acid, $\mathrm{mp} 186^{\circ} \mathrm{C}$, was dissolved in it, and evaporation was then continued to dryness. The residue was chromatographed in system I. The close relationship in the elution patterns of the radioactivity and the titration peak of the added lithocholic acid is shown in Figure 3. Fractions $(0.3 \mathrm{ml})$ from each tube in the peak (tubes 5 through 14) were combined and rechromatographed with system II. Radioactivity was assayed on planchets as with the preceding column, but the quantity of lithocholic acid in each tube was determined spectrophotometrically at $315 \mathrm{~m} \mu$ in a 9:1 mixture of $\mathrm{H}_{2} \mathrm{SO}_{4}$-glacial acetic acid after $15 \mathrm{~min}$ utes of heating at $60^{\circ} \mathrm{C}(13)$. Again, there was a close relationship between the elution of lithocholic acid, as determined spectrophotometrically, and the radioactivity, as is shown in Figure 4. The remaining material from

TABLE II

Specific activity of recrystallized lithocholic acid isolated from bile

\begin{tabular}{clccc}
\hline \hline Patient & \multicolumn{1}{c}{ Solvents } & Weight & & SA \\
\hline & & $m g$ & $c p m$ & $c p m / m g$ \\
C.A. & Petroleum ether & 2.760 & 79,400 & 28,800 \\
& Acetone & 2.285 & 68,400 & 29,600 \\
& Acetic acid- $\mathrm{H}_{2} \mathrm{O}$ & 1.028 & 31,400 & 30,600 \\
& Ethanol- $\mathrm{H}_{2} \mathrm{O}$ & 0.751 & 22,600 & 30,100 \\
& Acetone- $\mathrm{H}_{2} \mathrm{O}$ & 0.741 & 24,300 & 32,800 \\
& Acetic acid- $\mathrm{H}_{2} \mathrm{O}$ & 0.292 & 8,700 & 29,000 \\
L.R. & Petroleum ether & 2.920 & 61,950 & 27,100 \\
& Acetone & 2.790 & 71,150 & 26,900 \\
& Acetone & 1.268 & 33,100 & 26,100 \\
& Acetic acid- $\mathrm{H}_{2} \mathrm{O}$ & 0.818 & 21,790 & 26,700
\end{tabular}

tubes 5 through 14 was recrystallized six times in different solvents, and the specific activity remained relatively constant, as shown in Table II.

Conjugation with taurine and glycine. In order to determine the extent of conjugation of the labeled acid with taurine and glycine, $60 \mu 1$ of the bile-ethanol mixture collected during the first 4 hours of the experiment was chromatographed in system IV. Crystalline glycolithocholic acid, $\mathrm{mp} 213^{\circ} \mathrm{C}$, and taurolithocholic acid, mp $214^{\circ} \mathrm{C}$, were used as controls. The paper was run descending for 5 hours. The strip containing the radioactivity was cut into six zones that included both origin and solvent front. The remainder of the paper was developed with antimony trichloride to serve as a guide. Elution of the radioactivity from the six zones showed that $71 \%$ was in the glycolithocholic acid zone and $23 \%$ was in the taurolithocholic acid zone for C.A. For the second patient, L.R., $47 \%$ was in the glycolithocholic acid zone and $46 \%$ in the taurolithocholic acid zone.

Excretion of unconjugated lithocholic acid. In order to determine the amount of unconjugated labeled lithocholic acid in the bile, unhydrolized butanol extracts of 
bile were chromatographed on paper in system V. Development and elution of the papers as described in the preceding paragraph disclosed that 4 and $3.5 \%$ for C.A. and L.R., respectively, of the radioactivity on the paper was eluted from the zone corresponding to free lithocholic acid. The balance of the radioactivity remained at the origin, as did taurolithocholic acid, or moved only slightly with glycolithocholic acid.

Quantitation of bile acids in fistula bile. One one-hundredth aliquots from all fractions of bile collected for 24hour periods were pooled, and from this $1 \mathrm{ml}$ was diluted with $9 \mathrm{ml}$ of ethanol. One- $\mathrm{ml}$ fractions from this dilution were used for assays in triplicate. The fractions were hydrolyzed with $5 \mathrm{ml}$ of $4 \mathrm{~N} \mathrm{NaOH}$ in sealed glass tubes at $130^{\circ} \mathrm{C}$ for 6 hours. The hydrolysate was diluted with an equal volume of water, the $\mathrm{pH}$ was adjusted to 1 with concentrated $\mathrm{HCl}$, and the mixture was extracted five times with $20 \mathrm{ml}$ of ethyl ether. The ether was then evaporated, the residue dissolved in $65 \% \mathrm{H}_{2} \mathrm{SO}_{4}$, heated for 15 minutes, and the absorption spectrum determined from 240 to $400 \mu$ in a Beckman DL spectrophotometer. The concentrations of trihydroxy and dihydroxy bile acids were calculated after background corrections as previously described (14). The quantities excreted were as follows, in milligrams per 24 hours : for C.A., trihydroxy acids, 2.068: dihydroxy acids, 768; total, 2,836; and for L.R., trihydroxy acids, 582 ; dihydroxy acids, 250; total, 832 .

Content of lithocholic acid and deoxycholic acid in fistula bile. In order to determine if either lithocholic acid, other than that injected as tracer, or deoxycholic acid was present in the fistula bile, an overnight collection of bile (from 6 p.m. to 9 a.m., $410 \mathrm{ml}$ ) was hydrolyzed with $4.5 \mathrm{~N} \mathrm{NaOH}$ at $120^{\circ} \mathrm{C}$ for 5 hours at 15 pounds pressure. After the addition of $\mathrm{HCl}$ to give a $\mathrm{pH}$ of less than 1 , the hydrolysate was extracted with $10 \%$ ethyl ether in chloroform. The extract was chromatographed in system III. With this column, lithocholic acid is eluted with hexane and deoxycholic acid with 20 and $40 \%$ benzene in hexane.

The hexane fractions containing all the radioactivity present as lithocholic acid were combined and rechromatographed in system II. The tube representing the peak of the radioactivity eluted with $2 \%$ isopropyl ether contained $2,695 \mathrm{cpm}$, which accounted for $0.38 \mu \mathrm{g}$ of the lithocholic acid injected as tracer and $2.4 \%$ of all the radioactivity in the 15 -hour, overnight collection of bile. Paper chromatography of the contents of this tube in system $\mathrm{V}$ disclosed no spot in the region of the lithocholic acid control. Had there been as little as $1.67 \mathrm{mg}$ of lithocholic acid in the entire 15-hour collection of bile, $40 \mu \mathrm{g}$ would have to be present on the paper, a quantity easily detected as a blue, fluorescent spot with the $\mathrm{SbCl}_{3}$ reagent. The total quantity of dihydroxy and trihydroxy acids in the $410 \mathrm{ml}$ of bile was $520 \mathrm{mg}$. The sensitivity of the method used to detect lithocholic acid was sufficient to permit the conclusion that less than $0.3 \%$ of the total bile acids could have been present as lithocholic acid.

The fractions containing deoxycholic acid (20 and $40 \%$ benzene in hexane) were combined, and $0.0246 \mathrm{mg}$ of de- oxycholic acid 24- $\mathrm{C}^{14}$ having a specific activity of $8.95 \times 10^{6}$ $\mathrm{cpm}$ per $\mathrm{mg}$ was added to the combined fractions to serve as a marker. The residue was then rechromatographed in system III. The radioactivity appeared between tubes 15 and 42 , whereas the titratable acidity, mostly chenodeoxycholic acid, formed peaks between tubes 25 and 43 . Tubes 15 through 30 , containing the most radioactivity (deoxycholic acid, $140,710 \mathrm{cpm}$ ) with the least chenodeoxycholic acid $(22 \mathrm{mg})$, were rechromatographed in system III in order to provide better separation of the chenodeoxycholic acid from traces of the deoxycholic acid being sought. From this column, tubes 15 through 26 contained $87,600 \mathrm{cpm}$ (39.8\% of original amount put on) and about $3 \mathrm{mg}$ of dihydroxy acids. The contents of these tubes were combined and evaporated to a volume of $3 \mathrm{ml}$, and from this $60 \mu 1$ were chromatographed in system V. Chenodeoxycholic acid, $20 \mu \mathrm{g}$, and deoxycholic acid, $20 \mu \mathrm{g}$, were also put on the paper as controls. Development of the bile acid fluorescence with $\mathrm{SbCl}_{3}$ disclosed the presence of three fluorescent spots; one had the same position and fluorescent color as chenodeoxycholic acid, the second had a position intermediate between chenodeoxycholic and deoxycholic acid, and the third moved slightly behind deoxycholic acid and had a yellowish fluorescence, whereas deoxycholic acid fluorescence was blue, changing to orange with higher concentrations. There were no spots with the same position as deoxycholic acid, and hence it was possible to conclude that the total quantity of deoxycholic acid in the overnight collection of bile could not have exceeded $628 \mu \mathrm{g}$, or $0.11 \%$ of the total quantity of bile acids present.

\section{DISCUSSION}

The opportunity to study the metabolism of bile acids in human subjects in whom total exclusion of bile from the intestine can be proved occurs rarely and is of special value because extensive alterations produced by colonic bacteria in the bile acid molecule can be excluded and observations can be limited to the metabolism of these compounds occurring exclusively in the liver.

Under the conditions of these experiments. more than $90 \%$ of the radioactivity excreted in the bile was recovered as glycine or taurine conjugates of lithocholic acid. In contrast to the rat, which can rapidly metabolize lithocholic acid to $\beta$-muricholic acid (1) and other more hydrophilic bile acids (2), the enzyme systems in the human liver are apparently not so active. Only about 2 to $3 \%$ of the radioactivity appeared in other fractions eluted from the columns. At least four such metabolites could be detected in the two patients. In both, a small peak appeared just before chenodeoxycholic acid. In C.A., a second small peak occurred in the fractions containing cholic acid, but the ra- 


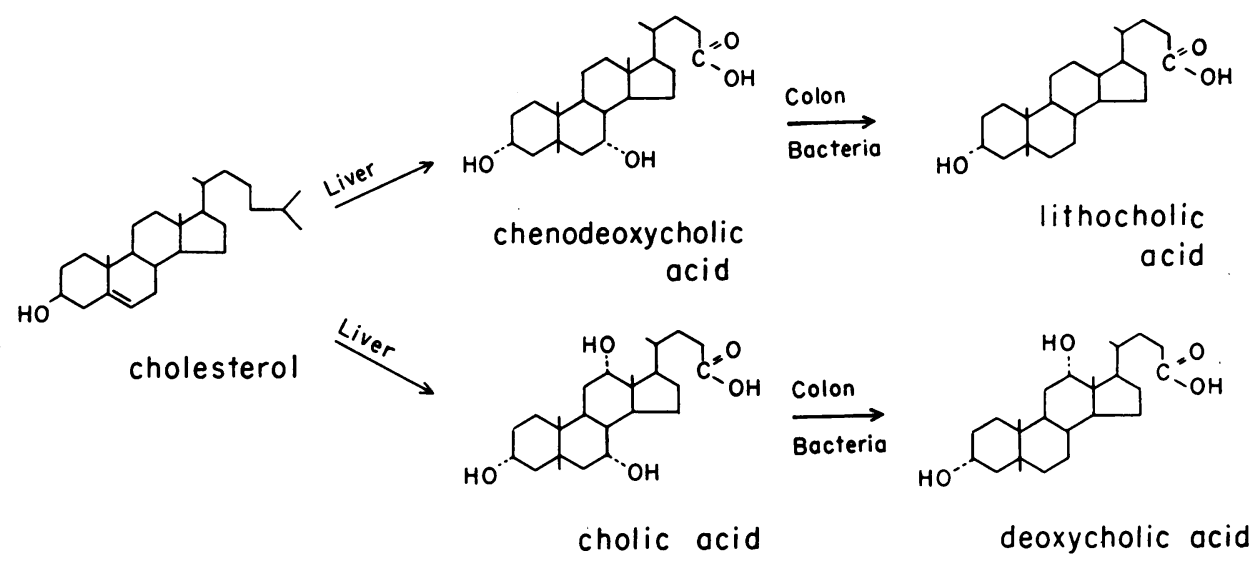

Fig. 5. Formation OF Lithocholic ACID AND DEOXYCholic ACID in MaN.

dioactive compound was not identical with cholic acid. In L.R., two additional peaks, one slightly less polar and the other more polar than chenodeoxycholic acid, were seen. It is thus possible for the human liver to transform lithocholic acid to other compounds, but only to a very limited extent, and for the most part lithocholic acid is not appreciably altered by the human liver and does not serve as an important precursor to other major bile acids formed by the liver.

Demonstration of the absence of lithocholic acid and deoxycholic acid in bile from patients with a complete external biliary fistula confirms similar observations made by Hellström and Sjövall (5) in their patient with T-tube drainage of the common duct. These observations also support the evidence recently reviewed by Bergström (15), that lithocholic acid and deoxycholic acid occur in human bile as a result of $7 \alpha$ dehydroxylation of chenodeoxycholic and cholic acid, respectively, by bacteria in the colon, and may thus be considered as secondary bile acids, since they are not formed primarily from cholesterol by the human liver. Norman and Shorb have recently demonstrated in vitro formation of lithocholic acid from chenodeoxycholic acid by microorganisms from human feces (16), and after intravenous administration of $\mathrm{C}^{14}$-chenodeoxycholic acid in man, lithocholic acid was found as the major labeled product in the feces (17). A diagram summarizing these observations is presented in Figure 5.

Of special interest was the observation that 3 to $4 \%$ of the radioactivity excreted in the bile was in the form of unconjugated lithocholic acid. Although the liver preferentially conjugates bile acids with amino acids, apparently this action is not obligatory for the excretion of bile acids into the bile. Bacterial cultures were not obtained because all of the bile was collected in ethanol and we did not anticipate this finding at the time of the experiment. It is unlikely, however, that the free $\mathrm{C}^{14}$-lithocholic acid resulted from bacterial action in the bile, since neither deoxycholic acid nor endogenous lithocholic acid could be detected in it. This finding agrees with Sjövall's studies which also showed trace amounts of free acids in human bile (18).

Another observation of interest in these patients with total bile fistula was that no significant quantity of $\mathrm{C}^{14}$ isotope from the labeled lithocholic acid could be found in the feces. This may be taken as evidence that direct excretion of bile acids from the blood across the intestinal wall is not an important route for elimination of bile acids from the body. The possibility remains that small quantities of bile acids could have undergone transintestinal excretion and absorption before reaching the colon, and hence the absence of bile acids in the feces does not completely exclude transintestinal excretion of bile acids in patients with bile fistula.

\section{SUMMARY}

Analysis of the biliary end products of intravenously administered $24-\mathrm{C}^{14}$-lithocholic acid in two patients with complete external biliary fistulas permitted the following observations. 1) Over $90 \%$ of the radioactivity excreted in the bile was recovered as conjugated lithocholic acid, indicating that this bile acid is not transformed by the 
human liver to other compounds to any appreciable extent. Very small quantities (2 to $3 \%$ ) of this acid, however; can be converted to other bile acids by the human liver. 2) Lithocholic acid and deoxycholic acid are not present in the bile of patients in whom bile is excluded from the intestine. 3) Free bile acids (unconjugated with taurine or glycine) can be excreted into the bile in small quantities by the human liver. 4) Transintestinal excretion of bile acids, if it occurs at all, is not a quantitatively important route for elimination of bile acids from the body in patients with a bile fistula.

\section{ACKNOWLEDGMENTS}

The authors are grateful to Dr. Richard Moore and Dr. Ivan Frantz for the use of their vibrating-reed electrometer equipment.

\section{REFERENCES}

1. Perry, G., and E. A. Doisy, Jr. Metabolism of lithocholic acid. Fed. Proc. 1959, 18, 301.

2. Bergström, S., J. Sjövall, and J. Voltz. Metabolism of lithocholic acid in the rat. Acta physiol. scand. 1953, 30, 22.

3. Wootton, I. D. P., and H. S. Wiggins. Studies in the bile acids. 2. The non-ketonic acids of human bile. Biochem. J. 1953, 55, 292.

4. Heftmann, E., E. Weiss, H. K. Miller, and E. Mosettig. Isolation of some bile acids and sterols from the feces of healthy men. Arch. Biochem. $1959,84,324$.

5. Hellström, K., and J. Sjövall. On the origin of lithocholic acid and ursodeoxycholic acid in man. Acta physiol. scand. 1961, 51, 218.

6. Bergström, S., M. Rottenberg, and J. Voltz. The preparation of some carboxyl labelled bile acids. Bile acids and steroids 2. Acta chem. scand. 1953, 7, 481.
7. Mosbach, E. H., C. Zomzely, and F. E. Kendall Separation of bile acids by column-partition chromatography. Arch. Biochem. 1954, 48, 95.

8. Matschiner, J. T., T. A. Mahowald, W. H. Elliot, E. A. Doisy, Jr., S. L. Hsia, and E. A. Doisy. Bile acids. I. Two new acids from rat bile. J. biol. Chem. 1957, 225, 771.

9. Sjövall, J. New solvents for the separation of bile acids with paper chromatography. Ark. Kem. 1955, 8, 299.

10. Sjövall, J. Separation of conjugated and free bile acids by paper chromatography. Bile acids and steroids 12. Acta chem. scand. 1954, 8, 339.

11. Carey, J. B., Jr., and H. S. Bloch. The rapid identification of bile acids with an antimony trichloride color reagent. J. Lab. clin. Med. 1954, 44, 486.

12. Watson, C. J. Studies of urobilinogen. III. The per diem excretion of urobilinogen in the common forms of jaundice and disease of liver. Arch. intern. Med. 1937, 59, 206.

13. Minibeck, $H$. Beiträge zur quantitativen fluoreszenzphotometrischen Mikroanalyse. II. Mitteilung: eine Method zur Bestimmung der Gallensäuren in Serum und im Serösen Flüssigkeiten mit dem "Fluoroquant." Biochem. Z. 1938, 297, 29.

14. Carey, J. B., Jr. The serum trihydroxy-dihydroxy bile acid ratio in liver and biliary tract disease. J. clin. Invest. 1958, 37, 1494.

15. Bergström, S. Metabolism of bile acids. Fed. Proc. 1962, 21, 28.

16. Norman, A., and M. S. Shorb. In vitro formation of deoxycholic and lithocholic acid by human intestinal microorganisms. Proc. Soc. exp. Biol. (N. Y.) 1962. 110. 552.

17. Carey, J. B., Jr., and G. Williams. Pathways of secondary bile acid formation as excretory metabolites of cholesterol: conversion of primary to secondary bile acids in man. J. Lab. clin. Med. 1962, 60,865 .

18. Sjövall, J. Bile acids in man under normal and pathological conditions. Clin. chim. Acta 1960, 5, 33.

\section{SPECIAL NOTICE TO SUBSCRIBERS}

Post Offices will no longer forward the Journal when you move.

Please notify The Journal of Clinical Investigation, Business Office, 10 Stoughton Street, Boston 18, Mass., at once when you have a change of address, and do not omit the zone number if there is one. 